\title{
A clinical study of ectopic pregnancy in a tertiary care hospital
}

\section{Arati Behera, Ranjita Ghadei*, Rudra Narayan Bal}

Department of Obstetrics and Gynecology, S. C. B. Medical College, Cuttack, Odisha, India

Received: 20 August 2018

Accepted: 27 September 2018

\section{*Correspondence:}

Dr. Ranjita Ghadei,

E-mail: drranjita_1971@rediffmail.com

Copyright: (c) the author(s), publisher and licensee Medip Academy. This is an open-access article distributed under the terms of the Creative Commons Attribution Non-Commercial License, which permits unrestricted non-commercial use, distribution, and reproduction in any medium, provided the original work is properly cited.

\section{ABSTRACT}

Background: Ectopic pregnancy is a life-threatening emergency commonly encountered by medical practitioner. Diagnosis is frequently missed and should be considered in any women in the reproductive age group with abdominal pain or vaginal bleeding. The aim of the study is to assess the incidence, clinical presentation, risk factors, methods of diagnosis, treatment, outcome and complications.

Methods: This was a prospective study at S.C.B. Medical college from January to December 2017. Parameters like age, parity, gestational period, risk factors, clinical presentations, findings on ultrasonogram and at surgery with morbidities associated with diagnosed cases of ectopic pregnancy $(n=93)$ were noted and analysed with SPSS-19 software.

Results: Incidence of ectopic pregnancy was 18/1000 deliveries. Maximum cases were in age group of 21 to 30 years $(54.8 \%)$ and parous $(76.3 \%)$. Common risk factors were having history of abortions $(46.2 \%)$, previous tubal sterilization $(24.7 \%)$, having one or more caesarean section $(17.2 \%)$ and h/o infertility (16.1\%). Most common symptom was pain abdomen (96.8\%). Commonest site was ampullo-isthmic region of tube and rupture was the commonest mode of presentation. All underwent laparotomy and unilateral salpingectomy was done in $86 \%$ of cases. It contributed to $3.27 \%$ of total maternal deaths.

Conclusions: Suspicion in high risk group can direct one to investigate and diagnose early, thereby reducing morbidity, mortality and improving the prospect of future fertility.

Keywords: Ampullo-isthmic region, Ectopic pregnancy, Laparotomy, Tubal sterilization, Unilateral salpingectomy

\section{INTRODUCTION}

An ectopic pregnancy occurs when a fertilised ovum implants outside the normal uterine cavity. ${ }^{1}$ It is one of the common causes of maternal morbidity and mortality in first trimester of pregnancy. ${ }^{2}$ The incidence of ectopic pregnancy has been increasing over past 3 decades. Worldwide ectopic pregnancy complicates 1 to $2.0 \%$ of all pregnancies. ${ }^{3}$

Risk factors for ectopic pregnancies are previous ectopic pregnancy, PID, infertility, previous tubal and abdominal surgeries. Additionally, ectopic pregnancy risk is increased following failure of contraception in the current cycle. In vitro fertilisation and embryo transfer also increase the risk of ectopic pregnancy in tubal factor infertility. ${ }^{4}$ Knowledge of risk factors helps to anticipate the condition in high risk category and early diagnosis prior to any emergent situation.

The classic symptom triad of ectopic pregnancy is pain abdomen, amenorrhea, and vaginal bleeding. ${ }^{5}$ Sensitive pregnancy testing, transvaginal ultrasonography and diagnostic laparoscopy have a major impact on early diagnosis of this condition. The hCG enzyme immunoassay, with a sensitivity of $25 \mathrm{mIU} / \mathrm{mL}$, is an accurate screening test for detection of ectopic pregnancy which allows the diagnosis of pregnancy before direct 
visualization by ultrasonography. The assay is positive in virtually all documented ectopic pregnancies. Evidence of an empty uterus, detection of adnexal masses and free peritoneal fluid, and adnexal ring are ultrasonographic signs of ectopic pregnancy. ${ }^{6}$ Current trend is a conservative way of management of these pregnancies by chemotherapeutic agents or conservative surgical approaches. $^{7,8}$

This study was undertaken at a tertiary teaching hospital to find out incidence, risk factors, presenting symptoms and management standards of ectopic pregnancy.

\section{METHODS}

This was a prospective study conducted in SCB Medical college O and G Department from January 2017 to December 2017.Out of 187 diagnosed cases of ectopic pregnancy 93 were selected at random. Patients presenting with pain abdomen, amenorrhea, vaginal bleeding were included in this study. Then culdocentesis and urine pregnancy test were carried out in hemodynamically unstable patients and those who were stable USG was done. Subsequently emergency laparotomy was done in hemodynamically unstable patients with provisional diagnosis of ruptured ectopic pregnancy. Only the cases of ectopic pregnancy confirmed by laparotomy were included in this study.

Patient characteristics like age, parity and risk factors for EP were noted. Mode of diagnosis, management modality, complications and need for blood transfusion were also recorded. The primary outcome measures studied were incidence of EP, their risk factors, mortality and morbidity in these women.

\section{Statistical analysis}

Data was entered in MS excel spreadsheet and analysed using SPSS software version 19.0. For categorical variables, data was compiled as frequency and percent. For continuous variables, data was calculated as mean \pm SD.

\section{RESULTS}

Total number of deliveries during present study period was 10071 and number of ectopic pregnancies was 187. Incidence of ectopic pregnancies during this period was $18 / 1000$ deliveries.

Table 1: Age distribution.

\begin{tabular}{|lll|}
\hline Age group (in years) & $\mathbf{N}(93)$ & $\%$ \\
$18-20$ & 04 & 4.3 \\
\hline $21-30$ & 51 & 54.8 \\
\hline $31-40$ & 35 & 37.6 \\
\hline$>40$ & 03 & 3.3 \\
\hline
\end{tabular}

Table 1 shows that the incidence of ectopic pregnancy is higher in 21 to 30 years of age. Youngest age was 18 years and highest age limit was 42 years. Highest incidence in the age group of 21 to 30 years denotes the peak of the fertile period after marriageable age.

Table 2: Parity.

\begin{tabular}{|lll|}
\hline Parity & $\mathbf{N}(93)$ & $\%$ \\
\hline Nulliparous & 22 & 23.7 \\
\hline 1 & 26 & 27.9 \\
\hline 2 & 37 & 39.8 \\
\hline$\geq 3$ & 08 & 08.6 \\
\hline
\end{tabular}

Table 2 shows that a major group of cases were of second parity $(39.8 \%)$. Nulliparous women constitute $23.7 \%$ of cases and $76.3 \%$ were parous women. Adoption of contraceptive measures like IUCD, progesterone only pills, permanent tubal sterilisation might be contributing towards the higher incidence in parous women than nulliparous. On the other way round, those who were not using any type of contraception might be adopting unwanted pregnancy termination and subsequently developing subclinical pelvic inflammation which is a casual factor for tubal ectopic pregnancy.

Table 3: Risk factors.

\begin{tabular}{|lll|}
\hline Risk factors & N (93) & $\%$ \\
\hline PID & 05 & 05.3 \\
\hline Sterilisation (tubectomy) & 23 & 24.7 \\
\hline H/O infertility & 15 & 16.1 \\
\hline H/O abortion & 43 & 46.2 \\
\hline Current contraception & 03 & 03.2 \\
\hline CS & 16 & 17.2 \\
\hline H/O ectopic pregnancy & 04 & 04.3 \\
\hline Other abdominopelvic surgery & 02 & 02.1 \\
\hline *some had more than one risk factors. & & \\
\hline
\end{tabular}

Table 3 shows risk factors of ectopic pregnancy. In this study history of (h/o) previous abortion was found in $46.2 \%$ of cases. Out of 43 women having h/o abortion, 27 $(62.7 \%)$ had induced it medically or surgically and 16 (37.3\%) had spontaneous abortion. In the group of women having $\mathrm{h} / \mathrm{o}$ induced abortion $12 \mathrm{had}$ induced it for $\geq 2$ times. Next common risk factors in the line were previous tubal sterilisation $(24.7 \%)$, having caesarean section $\geq 1$ time $(17.2 \%)$ and having $\mathrm{h} / \mathrm{o}$ infertility $(16.1 \%)$. History suggestive of PID was taken when all the three symptoms i.e., abdominal pain, fever, vaginal discharge were present. Only $5.3 \%$ of women had PID according to this criteria.

Table 4: Type of ectopic pregnancy.

\begin{tabular}{|lll|}
\hline Type & $\mathbf{N}(93)$ & $\%$ \\
\hline Chronic & 15 & 16.1 \\
\hline Acute & 78 & 83.9 \\
\hline
\end{tabular}


Table 4 shows most of the cases presented as acute ectopic pregnancy $83.9 \%$ and $16.1 \%$ cases presented as chronic ectopic pregnancy. No unruptured ectopic pregnancy was there in the study period. Being a tertiary care center the acute cases with haemodynamic instability might have been referred from lower centers for better care.

Table 5: Clinical presentation.

\begin{tabular}{|lll|}
\hline Clinical presentation & N $(93)$ & $\%$ \\
\hline Amenorrhea & 63 & 68.8 \\
\hline Pain abdomen & 90 & 96.8 \\
\hline Bleeding P/V & 29 & 31.2 \\
\hline Vomiting & 25 & 26.9 \\
\hline Syncope & 15 & 16.1 \\
\hline Shock & 20 & 21.5 \\
\hline UPT positive & 74 & 79.5 \\
\hline USG & 32 & 34.4 \\
\hline
\end{tabular}

Table 5 shows majority of women presented with pain abdomen (96.8\%), amenorrhea (68.8\%), bleeding $\mathrm{p} / \mathrm{v}$ $(31.2 \%)$. Many presented with vomiting (26.9\%), syncopal attack (16.1\%) and shock $21.5 \%$. Urine pregnancy test (UPT) was positive in $69.9 \%$ cases. Therefore $31.2 \%$ of patients presented before the missed period. Pallor was a significant finding in $64.5 \%$ of cases who required blood transfusion.

Table 6: Site of ectopic pregnancy.

\begin{tabular}{|llll|}
\hline \multicolumn{2}{|l|}{ Site of ectopic pregnancy } & N $(93)$ & $\%$ \\
Tube & & & \\
\hline \multirow{2}{*}{ Side } & Right & 47 & 50.5 \\
\cline { 2 - 4 } & Left & 41 & 44.1 \\
\hline \multirow{3}{*}{ Site } & Ampulla & 48 & 51.6 \\
\cline { 2 - 4 } & Isthmus & 15 & 16.1 \\
\cline { 2 - 4 } & Interstitium & - & - \\
\cline { 2 - 4 } & cornual & 06 & 6.5 \\
\hline \multirow{2}{*}{ Ovary } & & 03 & 3.2 \\
\hline
\end{tabular}

Table 6 shows that right side tubal pregnancy is more common than left side. Most common site of ectopic pregnancy was in ampulla of fallopian tube $51.6 \%$.Isthmic tubal pregnancy was seen in $16.1 \%$ and $6.5 \%$ cases had cornual pregnancy. Only $3.2 \%$ had ovarian pregnancy.

Table 7: Distribution according to different morbidities.

\begin{tabular}{|lll|}
\hline Morbidities & N $(93)$ & $\%$ \\
\hline Shock & 20 & 21.5 \\
\hline GA & 28 & 30.1 \\
\hline BT & 60 & 64.5 \\
\hline ICU admission & - & - \\
\hline
\end{tabular}

Table 7 shows blood transfusion was required in 60 $(64.5 \%)$ cases. $20(21.5 \%)$ women presented with shock. Total number of maternal deaths were 122 and 4 deaths were caused due to ectopic pregnancy. So maternal mortality rate due to ectopic pregnancy was $3.27 \%$.

\section{Table 8: Distribution according to modality of treatment.}

\begin{tabular}{|llll|}
\hline Treatment & & N (93) & $\%$ \\
\hline \multirow{2}{*}{ Salpingectomy } & U/L & 77 & 82.8 \\
\cline { 2 - 4 } & B/L & 13 & 14.0 \\
\hline & Salpinge-oopherectomy & 2 & 2.1 \\
\hline & Oopherecctomy & 1 & 1.07 \\
\hline
\end{tabular}

Table 8 shows all patients underwent laparotomy. One had oophorectomy for ovarian pregnancy and two had salpingeoopherectomy for ovarian pregnancy along with adnexal adhesion. All but 2 of the cases treated with B/L salpingectomy had previous tubal sterilisation.

\section{DISCUSSION}

Incidence of ectopic study in present study is $18 / 1000$ deliveries. In Saudi Arabia the frequency of ectopic pregnancy was $0.58 \%$ of deliveries. ${ }^{9}$ The incidence of $1.1 \%$ of deliveries in a Nigerian study. ${ }^{10}$ Frequency of ectopic pregnancy in Pakistan was $1.3 \%$ of total 3252 pregnancies. ${ }^{11}$ The incidence of ectopic pregnancies of $7.4 / 1000$ deliveries in Bangladesh. ${ }^{12}$ In a study by Sethy $S$, incidence of ectopic pregnancy was 5.6/1000 deliveries in india. ${ }^{13}$ In a study conducted by Gaddagi $\mathrm{R}$ and Chandrashekhar AP, the incidence was 1:399 pregnancies. ${ }^{14}$ In Porwal $S$ et al study, the incidence was 2.46 per thousand of deliveries. ${ }^{15}$ The incidence of EP was $0.91 \%$ in a study by tahmina. ${ }^{16}$ The increase in incidence is associated with rise in the incidence of sexually transmitted infections (STIs) and salpingitis, advances in assisted reproductive technology, tubal surgeries, female contraception and earlier diagnosis with more sensitive methods.

EP accounts for $3.5-7.1 \%$ of maternal mortality in India. ${ }^{17,18}$ Maternal mortality in present study is $3.27 \%$. More cases were seen between age group 21-30 years $(54.8 \%)$ in present study which is similar to other studies conducted by Tuli AG et al, Spandana $\mathrm{N}$ et al. ${ }^{19,20}$

The most important cause of ectopic pregnancy is damage to the tubal mucosa may be due to infections, which could obstruct embryo transport due to scarring. In present study $46.2 \%$ had previous $\mathrm{H} / \mathrm{O}$ abortions. In a study by Tuli AG et al, it was $28.5 \% .{ }^{19}$ In Asuri et al study PID accounts for $25.6 \%$ of ectopic pregnancy. ${ }^{21}$ In Tahmina et al $15.3 \%$ and Porwal S et al it is $15.3 \%$ and $47.5 \%$ respectively. ${ }^{15,16}$

In present study $\mathrm{H} / \mathrm{O}$ infertility was found in $16.1 \%$ which is comparable to other studies like $12.9 \%$ in Tuli AG et al study. ${ }^{19}$ In present study $4 \%$ cases had previous $\mathrm{H} / \mathrm{O}$ previous ectopic pregnancy. Shaista et al found an increased incidence of ectopic pregnancies (9\%) in women with previous history of ectopic pregnancy. ${ }^{9}$ In 
AG Tuli et al, Asuri et al and N Spandana, it is 9\%, 6.4\%, $10 \%$ respectively. ${ }^{19-21}$

In the present study abdominal pain and amenorrhoea were present in $96.8 \%$ and $68.8 \%$ of cases respectively. Gaddagi et al obsereved that $89.2 \%$ presented with pain abdomen, $75.7 \%$ with amenorrhoea and $43.2 \%$ with spotting per vaginum. In present study all cases were managed surgically, and a salpingectomy was performed by laparotomy as present hospital is a tertiary level hospital and all patients referred were hemodynamically unstable. Most studies reported a similarly high rate of surgical management. ${ }^{14,20,21}$

\section{CONCLUSION}

All patients in present study presented late following rupture or tubal abortion.so all patients underwent laparotomy and total salpingectomy. Hence there is a need of education and awareness creation among women of reproductive age regarding risk factors and early warning symptoms of ectopic pregnancy. High degree of suspicion on basis of risk factors at primary level of health care delivery system and early diagnosis with essential aids like transvaginal ultrasound and serial $B$ hCG estimation, timely intervention in the form of medical and surgical treatment will help in reducing the morbidities like blood transfusion, exposure to general anaesthesia, laparotomy, consequences on future fertility and mortality associated with ectopic pregnancy and to improve the future reproductive outcome.

\section{Funding: No funding sources}

Conflict of interest: None declared

Ethical approval: The study was approved by the Institutional Ethics Committee

\section{REFERENCES}

1. Walke JJ. Ectopic pregnancy. Clin Obstet Gynecol. 2007;50:89-99.

2. Mahheob U, Masher SH. Management of ectopic pregnancy, a two year study. Ayub Meb Coll Abbotthad. 2006;18(4);34-7.

3. Jurkvic D. Diagnosis and management of ectopic pregnancy. British Med J. 2011;342:3397.

4. Li C, Zhao WH, Zhu Q, Cao SJ, Ping H, Xi X, et al. Risk factors for ectopic pregnancy: a multi-center casecontrol study. BMC Preg Childbirth. 2015;15(1):187.

5. Prasanna B, Jhansi CB, Swathi K, Shaik MV. A study on risk factors and clinical presentation of ectopic pregnancy in women attending a tertiary care centre. IAIM. 2016;3(1):90-6.

6. Berek S. Bereck and Novak's Gynecology. $15^{\text {th }}$ ed; 2012:628-630.
7. Sultana CJ, Easley K, Collins RL. Outcome of laparoscopic vs traditional surgeries for ectopic pregnancies. Fertil steril. 1992;57:285.

8. Delacruz A. Cumming DC. The factors which determine the fertility after a conservative or radical surgical treatment for ectopic pregnancy. Fertil steril. 1997;68:871.

9. Shaista A, Bothaina AW, Hussain AS. Frequency of EP in a medical centre, kingdom of Saudi Arabia. JPMA. 2011;61:221

10. Igwegbe AO, Eleje GU, Okpala BC. An appraisal of the management of ectopic pregnancy in a Nigerian tertiary hospital. Annals of medical and health sciences research. 2013;3(2):166-70.

11. Khaleeque F, Siddiqui RI, Jafarey SN. Ectopic pregnancies: A three year study. J Pak Med Assoc. 2001;51(7):240-4.

12. Yeasmin MS, Uddin MJ, Hasan E. A clinical study of ectopic pregnancies in a tertiary care hospital of Chittagong, Bangladesh. Chattagram Maa-O-Shishu Hosp Med Coll J. 2014;13(3):1-4.

13. Shetty S, Shetty A. A clinical study of ectopic pregnancies in a tertiary care hospital of Mangalore, India. Innov J Med Health Sci. 2014;4(1).

14. Gaddagi RA, Chandrashekhar AP. A clinical study of ectopic pregnancy. JCDR. 2012;6:867-9.

15. Gupta R, Porwal S, Swarnkar M, Sharma N, Maheshwari P. Incidence, trends and risk factors for ectopic pregnancies in a tertiary care hospital of Rajasthan. JPBMS. 2012;16(07):1-3.

16. Tahmina S, Daniel M, Solomon P. Clinical analysis of ectopic pregnancies in a tertiary care centre in Southern India: a six-year retrospective study. JCDR. 2016;10(10):QC13.

17. Shah P, Shah S, Kutty RV, Modi D. Changing epidemiology of maternal mortality in rural India: time to reset strategies for MDG-5. Trop Med Int Health. 2014;19(5):568-75.

18. Yadav K, Namdeo A, Bhargava M. A retrospective and prospective study of maternal mortality in a rural tertiary care hospital of Central India. Indian J Comm Health. 2013;25(1):16-21.

19. Tuli AG, Goyal S, Livingston D, Kurian AS. Ectopic pregnancy: a five year retrospective study in a tertiary care hospital. Int J Reprod Contracept Obstet Gynecol. 2015;4:1400-3.

20. Spandana N, Togarikar SM, Polepaka D. A retrospective study of ectopic pregnancy in a teritary care hospital. JMSCR. 2016;4(4):9985-8.

21. Asuri SS, Kalpana P. A clinical study of ectopic pregnancy. Int J Reprod Contracept Obstet Gynecol. 2016;5:3750-3.

Cite this article as: Behera A, Ghadei R, Bal RN. A clinical study of ectopic pregnancy in a tertiary care hospital. Int J Reprod Contracept Obstet Gynecol 2018;7:4461-4. 